Neurosurg Focus 25 (6):E11, 2008

\title{
Spontaneous encephaloceles of the temporal lobe
}

\author{
Joshua J. Wind, M.D., Anthony J. Caputy, M.D., and Fabio Roberti, M.D. \\ Department of Neurological Surgery, George Washington University, Washington, DC
}

\begin{abstract}
Encephaloceles are pathological herniations of brain parenchyma through congenital or acquired osseus-dural defects of the skull base or cranial vault. Although encephaloceles are known as rare conditions, several surgical reports and clinical series focusing on spontaneous encephaloceles of the temporal lobe may be found in the otological, maxillofacial, radiological, and neurosurgical literature. A variety of symptoms such as occult or symptomatic CSF fistulas, recurrent meningitis, middle ear effusions or infections, conductive hearing loss, and medically intractable epilepsy have been described in patients harboring spontaneous encephaloceles of middle cranial fossa origin. Both open procedures and endoscopic techniques have been advocated for the treatment of such conditions. The authors discuss the pathogenesis, diagnostic assessment, and therapeutic management of spontaneous temporal lobe encephaloceles. Although diagnosis and treatment may differ on a case-by-case basis, review of the available literature suggests that spontaneous encephaloceles of middle cranial fossa origin are a more common pathology than previously believed. In particular, spontaneous cases of posteroinferior encephaloceles involving the tegmen tympani and the middle ear have been very well described in the medical literature. (DOI: 10.3171/FOC.2008.25.12.E11)
\end{abstract}

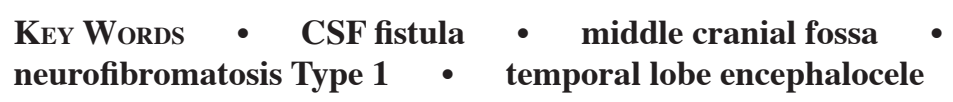

$\mathrm{C}$ RANIAL encephaloceles are rare conditions, with a reported overall incidence of approximately 1 in 35,000 people. ${ }^{25}$ Although the majority of cases are associated with an initiating process (such as a trauma, neoplasm, inflammatory condition, or previous surgical procedure), these circumstances may also be absent, thus leading to the less common diagnosis of spontaneous encephaloceles of idiopathic origin. ${ }^{25,26,56}$ Encephaloceles are reportedly most common in the anterior cranial fossa, but they occur in the middle cranial fossa as well. Temporal lobe encephaloceles are defined as pathological herniations of brain parenchyma through dura mater and bone and involve the middle cranial fossa or the laterotemporal cranial vault. Sphenoidal, temporal, and parietal bones form the osseous boundaries of the middle cranial fossa. An anatomical classification of spontaneous temporal encephaloceles based on site of origin has been previously proposed by Wilkins and Radtke in $1993 .{ }^{56}$ Several operative reports and surgical case series regarding the treatment of these conditions may be found in the otological, maxillofacial, radiological, and neurosurgical literature..$^{14,57} \mathrm{We}$ present a multidisciplinary review on the topic and discuss the diagnosis and management of temporal lobe encephaloceles (Table 1).

Spontaneous temporal lobe encephaloceles are defined as brain herniations of middle cranial fossa origin not associated with traumatic, neoplastic, inflammatory, or iatrogenic conditions. These lesions may become clinically manifest during either childhood or adulthood. De-

Abbreviation used in this paper: NF1 = neurofibromatosis Type 1 . pending on the anatomical location, patient age at presentation, and associated pathological conditions of these lesions, they may present along with signs of occult or symptomatic CSF fistulas, recurrent meningitis, middle ear effusions, otitis, conductive hearing loss, or medically intractable epilepsy.

\section{Classification}

Sphenoidal encephaloceles may involve either the body or the greater wing of the sphenoid bone. ${ }^{11,47}$ Defects involving the vertical portion of the greater sphenoid ala may allow protrusion of cerebral matter into the posterior orbital region, leading to the onset of slowly progressive, pulsating proptosis (sphenoorbital or posterior orbital encephalocele). This condition has been described to more commonly affect young women (female to male ratio of $5: 3)^{7,51}$ and patients suffering from NF1. ${ }^{30}$ Orbital osseous dysplasia with hypoplasia of both greater and lesser sphenoid wings, deformity of the lateral aspect of the sphenoid body, and/or enlargement of the superior orbital fissure may occur in patients with NF1. In this uncommon clinical subtype of NF1 (cranioorbital-temporal neurofibromatosis), orbital neurofibromas are associated with sphenoorbital encephaloceles and pulsating exophthalmos. ${ }^{60}$ Encephaloceles protruding into the infratemporal fossa or pterygopalatine fossa, or toward the lateral wall of the nasopharynx (anteroinferior or transalar encephaloceles) are commonly associated with deficits involving the horizontal portion of the greater sphenoidal wing, laterally to the cranial base foramina of the sphenoidal bone (foramen ovale and rotundum). ${ }^{11,15,21,28,36,47,49,50,55}$ Such en- 
cephaloceles may either remain clinically occult until adulthood, and then present with nonspecific symptoms, ${ }^{47}$ or constitute the pathological substrate of a cohort of patients without mesial sclerosis who suffer from medically refractory temporal lobe epilepsy. ${ }^{11,15,28,42,44}$

Osseous defects located in the anteromedial portion of the middle cranial fossa, or more medially in the region of the sphenoidal wing foramina, could lead to the genesis of encephaloceles protruding into the sphenoid sinus or its lateral recess (anteromedial or lateral sphenoidal encephaloceles). ${ }^{2,3,5,6,9,10,12,25-27,33,37,40,41,52,54,58}$ Patients harboring this type of lesion classically present during adulthood with signs and symptoms of CSF rhinorrhea, the subclinical courses of which may lead to recurrent episodes of meningitis and delayed diagnosis. ${ }^{13,23,24}$ Herniations of temporal lobe parenchyma and/or meninges may also involve the posterior temporalis bone at the level of the tegmen tympani (posteroinferior or aural encephaloceles). Although the tegmen tympani remains the more common location for temporal bone encephaloceles, ${ }^{16,31,46,53}$ lesions involving the mastoid cavity as well as the petrous apex have been described in the literature. ${ }^{34,35,45}$ Although middle ear effusions, recurrent ear infections, and progressive hearing loss are the most common findings at presentation, cases of medically refractory temporal lobe epilepsy have also been reported in association with posteroinferior encephaloceles. ${ }^{31,46,57}$

\section{Pathogenesis}

Poorly understood congenital and embryological factors are believed to be involved in the pathogenesis of spontaneous encephaloceles of the temporal lobe, and few theories have been postulated to explain the location and idiopathic nature of such lesions..$^{11,15,28}$ With the exception of its base and the medial portion centered on the foramen rotundum (which ossifies following a cartilaginous stage beginning 8 weeks after conception), the great ala of the sphenoid ossifies in membranes, fusing with the body and the small ala at the end of the 1st year of life. ${ }^{43}$ Up to 19 ossification centers appear to be involved in this ossification process during a normal embryological life. ${ }^{11}$ A developmental problem occurring at an early embryological stage could therefore lead to the formation of a nonossified membranous ala, thus favoring the formation of spontaneous encephaloceles at this level. ${ }^{11,28}$ The incomplete development and fusion of the medial aspect of the sphenoid bone may also lead to the formation of a persistent lateral craniopharyngeal canal, known as the Sternberg canal. This rare cranial base abnormality may then act as the site of origin for congenital encephaloceles protruding into the lateral recess of the sphenoid sinus. ${ }^{8}$ As for the temporal bone, the presence of small areas of dehiscence or bone thinning on and around the tegmen tympani is not an uncommon anatomical finding. This occurrence is, in fact, very well known by neurootologists and skull base surgeons who are familiar with the surgical anatomy of the middle cranial fossa. ${ }^{16}$ Multiple areas of bone dehiscence of the tegmen tympani and petromastoid region have been found in up to $34 \%$ of dissected temporal bones in postmortem anatomical studies,

\section{Table 1: Classification of temporal lobe encephaloceles}

\begin{tabular}{l}
\hline temporal encephaloceles \\
lateral (defect involves the pterion/asterion/cranial vault) \\
anteroinferior/transalar (defect involves the anteroinferior portion \\
of the middle fossa) \\
posteroinferior (defect involves the tegmen tympani) \\
sphenoidal encephaloceles \\
sphenoorbital/posterior-orbital (defect involves the sphenoid wing) \\
anteromedial (defect involves the anteromedial portion of the \\
middle fossa)
\end{tabular}

with bilateral deficits described in $20 \%$ of the specimens examined by Kapur et al. ${ }^{1,22}$ Idiopathic meningoencephaloceles of the middle ear occur most frequently around the seventh decade of life, ${ }^{4}$ and Moreano and associates ${ }^{32}$ in an anatomical study involving 1000 human temporal bones observed an inverse relationship between thinning of the temporal bone around the carotid artery and age of the dissected anatomical specimen. A thin bone covering was observed in $17.3 \%$ of temporal bones in specimens 40 years old or older, whereas such thinning was present in only $8.3 \%$ of younger specimens.

Small bone perforations involving the floor of the middle cranial fossa (the so-called "pit-holes") also constitute known natural variations of the temporal bone anatomy. ${ }^{38}$ Nevertheless, the occurrence of these osseous defects alone does not appear to be sufficient to promote the development of a pathological herniation, as the incidence of meningoceles is far less than the reported occurrence of such bone dehiscences. ${ }^{17}$ Progressive dural and osseous thinning secondary to changes in CSF pressure could also be involved in the genesis of spontaneous encephaloceles and low-normal pressure fistulas in adults, as previously described in the literature. ${ }^{23,24}$ Many factors such as early developmental disorders, osseous anatomical variations, aging and bone remodeling, erosive arachnoid granulations, and low-grade inflammation have all been proposed as factors in the pathogenesis of spontaneous temporal encephaloceles, but the mechanisms involved in the formation of these meningoencephalocele herniations remain controversial. ${ }^{19}$

\section{Diagnosis}

Prompt clinical diagnosis and correct neuroradiological localization of the site of the fistula/herniation are keys for successful treatment of symptomatic temporal lobe encephaloceles. In the presence of a CSF leak any diagnostic delay may reasonably increase the risk of bacterial meningitis, with a reported incidence of CSF infection that varies from 9 to $50 \% .^{18}$ Recurrent episodes of clinical or subclinical meningitis may also occur, provided that the natural course of a reactive inflammatory response does not always lead to the spontaneous healing of a fistulous tract. Cases that manifest with CSF rhinorrhea may be confirmed by assessing both the levels of glucose and contents of asialo-transferrin (beta-2 transferrin) in the nasal discharge. In patients with normal serum glucose levels, 
a concentration of glucose $>30 \mathrm{mg} / \mathrm{dl}$ in the collected sample is considered suspicious for a CSF leak. Dextrose sticks, although easy to use and readily available, have a low specificity for detecting CSF in the nasal discharge. The presence of substances that reduce lacrimal and nasal secretions may lead to a false positive result of this test even in the presence of low concentrations of glucose. Therefore, in cases in which nasal discharges can be collected, the measurement of beta- 2 transferrin remains the first-line test for the diagnosis of a CSF fistula. This polypeptide involved in ferrous Fe transport may be detected only in the CSF, aqueous humor, and perilymph, and its discovery in a nasal discharge has high specificity and sensitivity for the confirmation of a clinically suspected CSF leak.

Once the diagnosis of a CSF leak has been made, an accurate radiological localization of the site of the fistula should be obtained. Localization of such areas may sometimes be challenging, and this is particularly true in cases of nontraumatic and/or intermittently active CSF leaks. High-resolution CT scans have a low sensitivity for the diagnosis of osseous-dural defects and associated rhinorrhea. Nevertheless, we found the indirect and 3D information provided by this noninvasive modality to be very useful in both preoperative planning and in the selection of a tailored surgical approach for definitive repair. Better accuracy may be obtained using cisternal injection of water-soluble contrast medium and its subsequent radiological visualization at the level of the osseous-dural defect (CT cisternography). Although this modality has a good sensitivity for the diagnosis of active leaks (80-85\%), intermittent or inactive fistulas are usually associated with a high incidence of false negative results and low sensitivity. ${ }^{18}$ Magnetic resonance imaging with cisternography or constructive interference in steady-state protocols is commonly used in the diagnosis of CSF fistulas, and preliminary results suggest that these flow-sensitive MR imaging studies may have an important role in the evaluation of CSF leaks involving the skull base. ${ }^{29}$ Such examinations provide the advantages of noninvasiveness, excellent anatomical details, and the absence of ionizing radiation, and their sensitivity in the identification of the site of fistulas has been reported to be as high as 100\%, even in patients with inactive fistulas. ${ }^{18}$ We believe that an MR imaging evaluation should also be performed in all cases of spontaneous CSF leaks to rule out associated or predisposing conditions such as hydrocephalus or destructive skull-base neoplasms. At our institution we routinely obtain flow-sensitive MR imaging sequences in conjunction with 3D CT in all patients with a clinical or suspected diagnosis of a CSF fistula. Radionuclide cisternography with the use of intranasal pledgets has been used in the past to confirm the diagnosis of intermittent or slow CSF leaks. ${ }^{39}$ Although the information provided by this invasive study may be useful in cases in which a discharge cannot be collected (such as low volume or drainage through the rhinopharynx), its sensitivity for the identification of sites of fistulas remains low, and especially in cases of uncooperative patients, the information provided can be misleading. ${ }^{18}$

\section{Surgical Treatment}

Definitive surgical repair of spontaneous encephaloceles of the temporal lobe is warranted in cases of persistent or recurrent symptoms. In general the appropriate surgical treatment should be selected and tailored according to presenting symptoms, location of the lesion, and presence and type of the CSF leak, as well as the general medical condition and expectations of the patient. In cases of active CSF fistulas, all of the appropriate medical management should be started while completing the neuroradiological workup. Bed rest with head elevation, as well as general precautions to avoid increases in intracranial pressure, is commonly recommended in such cases. Also, placement of an indwelling lumbar catheter for continuous or intermittent CSF drainage may serve the 3 purposes of minimizing the leak at the site of herniation, allowing for the preoperative or intraoperative injection of fluorescein dye, and decreasing the CSF pressure after definitive surgical repair.

The ideal operative approach should allow full exposure and visualization of the encephalocele and its surgical reduction/amputation, as well as definitive repair of the associated osseous-dural defect. Open surgical repairs has been the classic approach to treatment of symptomatic encephaloceles in the past. Anteromedial, anteroinferior, and posteroinferior encephaloceles can be treated using either intracranial or extracranial routes. For open intracranial access, frontotemporal or temporal craniotomies (with the optional addition of a zygomatic osteotomy or zygomaplasty) can be performed to reach and repair lesions involving either the temporal or sphenoidal component of the middle cranial fossa as well as the lateral extension of the sphenoid sinus (lateral sphenoidal recess). ${ }^{9,26}$ Once the area of herniation has been located, usually by means of an extradural dissection, the final repair may be performed intradurally, extradurally, or by combining the two routes. When possible, we prefer to reduce/amputate the encephalocele extradurally, repairing any osseous defect before considering the addition of an intradural exposure, so as to confine any nonsterile sinus cavity before entering the arachnoidal plane. Although performing a duraplasty with a directly sutured fascial autograft (or any allograft of choice) would be ideal in these situations, such a possibility is hardly allowed, if not precluded, by the anatomical location of the vast majority of temporal encephaloceles.

After the herniated parenchyma has been amputated and hemostasis achieved, the osseous defect may be repaired using fat, local muscle, fascia, calvarial graft, bone chips, or some combination of these. ${ }^{26,59}$ When dealing with anteroinferior or posteroinferior lesions, a vascularized flap of temporoparietal pericranium can also be harvested to cover the osseous repair and act as an onlay graft over the area of dural deficiency (see Illustrative Case). We prefer to avoid splitting the temporal muscle during the repair to minimize the risks of postoperative muscular atrophy and related cosmetic issues. Extracranial procedures such as transfacial approaches, LeFort osteotomies, and midfacial degloving techniques have also been used for the repair of anteromedial and antero- 


\section{J. J. Wind, A. J. Caputy, and F. Roberti}
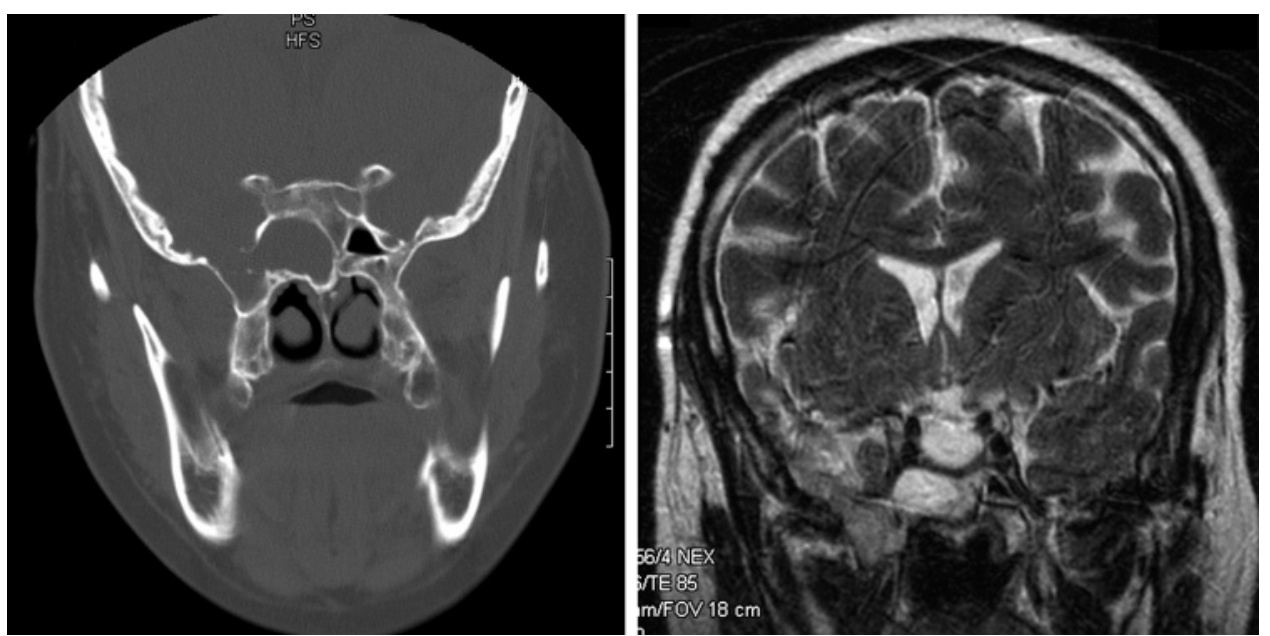

FIG. 1. Coronal preoperative CT scan (left) and T2-weighted MR image (right) show the osseous defect located lateral to the foramen rotundum on the right, and the associated anteroinferior encephalocele.

inferior encephaloceles. ${ }^{20,33,41}$ Although these procedures offer the benefit of avoiding consequences directly related to brain manipulation (such as seizure, contusion, or postoperative brain edema), the possibility of a thorough exploration of the middle cranial fossa may be limited when using these routes, thus restricting their usefulness in cases of unclear preoperative localization of the area involved by the dural defect.

Frontotemporal extradural approaches, with or without posterior orbital osteotomy and/or orbital cranioplasty, may be used to repair sphenoorbital encephaloceles, whereas lateral temporal encephaloceles are usually treated with a standard frontotemporal or temporal craniotomy centered over the osseous-dural defect. ${ }^{14}$

Posteroinferior encephaloceles involving the tegmen tympani can also be treated using a partial mastoidectomy, with or without the addition of a subtemporal approach for a combined intracranial-extracranial repair. ${ }^{31,48,59}$ Such an extradural transpetrosal route allows the combination of both encephalocele repair and surgical toilette of the mastoid, also avoiding the need for brain manipulation. Failure to seal both the dural defect and open air cells during this procedure may lead to recurrent episodes of indolent CSF leaks through the posterior pharynx (via the middle ear and eustachian tube); therefore, an endoscopic examination of the oral cavity should be performed in the early postoperative period in dubious cases.

With the advent of endoscopic approaches to the skull base, the surgical armamentarium for treating basal encephaloceles has greatly expanded. These procedures carry the benefit of minimizing brain manipulation while also avoiding the need for cutaneous incisions. On the other hand, definitive dural reconstruction during endoscopic approaches (using onlay/inlay techniques and/or vascularized flaps) may sometimes be challenging. Although often described as minimally invasive techniques, the extent of anatomical dissection that is sometimes required to expose and repair certain osseous-dural defects by means of endoscopic techniques should not be minimized. Therefore, before considering such routes, surgeons should become familiar with sinus endoscopic anatomy, equipment, surgical techniques, and management of related complications. Specific approaches are dictated by presenting symptoms and the exact location of the encephalocele, with the addition of the careful preoperative evaluation of the patient's individual sinus anatomy. Within the middle cranial fossa, the anteromedial encephaloceles have been the lesions most commonly approached using endoscopic techniques, mainly due to their proximity to easily accessible sinus routes. These encephaloceles may be repaired via either an endoscopic transnasal transsphenoidal or transethmoidal route..$^{6,25,40,52}$ Although the surgical anatomy for a direct transsphenoidal approach is familiar to the majority of surgeons, this approach may not always provide complete visualization of the lateral recess of the sphenoid sinus, often the site of the defect. For endoscopic access to this area, a transmaxillary transpterygoid approach has also been advocated. In this case, following a standard endonasal sphenoethmoidectomy, the posterior wall of the maxillary sinus is removed, allowing entrance into the pterygopalatine fossa. The lateral recess of the sphenoid sinus is then entered via direct drilling of the pterygoid process. ${ }^{3}$

In conclusion, a wide array of surgical techniques, such as a combination of open intracranial and extracranial as well as endoscopic approaches, is now available to otolaryngologists and neurosurgeons for the treatment of symptomatic temporal lobe encephaloceles. A thorough understanding of the anatomy of any individual bonedural defect as well as a meticulous preoperative workup may allow surgeons to provide successful individualized surgical planning, tailoring the appropriate management on a case-by-case basis.

\section{Case Illustration}

This 61-year-old woman presented to our institution with clinical symptoms consistent with meningitis. Her medical history showed recurrent episodes of spontaneous rhinorrhea and her neuroradiological workup revealed the presence of a middle fossa osseous dehiscence associated with a lateral temporosphenoidal encepha- 


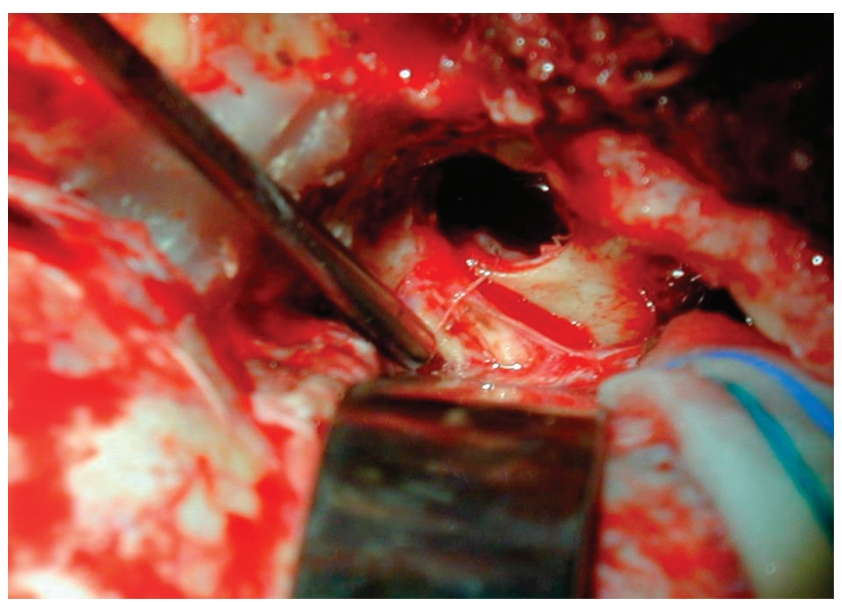

FIG. 2. Intraoperative photograph showing the bone-dural dehiscence lateral to V2 after amputation of the encephalocele.

locele (anteroinferior variant; Fig. 1). An ipsilateral temporal mass consistent with an intraparenchymal abscess was also identified. Computed tomography cisternography confirmed the presence of a CSF fistula in the region of the encephalocele. The patient underwent an elective frontotemporal craniotomy with stereotactic aspiration of the abscess, extradural middle fossa exploration, amputation of the encephalocele, and repair of the osseous dehiscence via the transposition of a vascularized temporoparietal pericranial flap (Fig. 2). The rhinorrhea resolved and the patient remains asymptomatic (Fig. 3).

\section{Disclaimer}

The authors report no conflict of interest concerning the materials or methods used in this study or the findings specified in this paper.

\section{References}

1. Ahren C, Thulin CA: Fatal intracranial complications due to politerization of the outer ear canal in otitis therapy, caused by intracranial temporal bone defects. Sven Lakartidn 61:24212437, 1964

2. Albernaz MS, Horton WD, Adkins WY, Garen PD: Intrasphenoidal encephalocele. Otolaryngol Head Neck Surg 104:279-281, 1991

3. Al-Nashar IS, Carrau RL, Herrera A, Snyderman CH: Endoscopic transnasal transpterygopalatine fossa approach to the lateral recess of the sphenoid sinus. Laryngoscope 114:528532,2004

4. Aristegui M,Falcioni M, Saleh E, Taibah A, Russo A, Landolfi $\mathrm{M}$, et al: Meningoencephalic herniation into the middle ear: a report of 27 cases. Laryngoscope 105:512-518, 1995

5. Bikmaz K, Cosar M, Iplikcioglu AC, Dinc C, Hatiboglu MA: Spontaneous cerebrospinal fluid rhinorrhoea due to temporosphenoidal encephalocele. J Clin Neurosci 12:827-829, 2005

6. Bolger WE: Endoscopic transpterygoid approach to the lateral sphenoid recess: surgical approach and clinical experience. Otolaryngol Head Neck Surg 133:20-26, 2005

7. Bornemann A, Schwarz M, Bruhl K, Goebel HH: A sphenoorbital encephalocele-clinical, radiological, and morphological findings. Neurosurg Rev 11:205-206, 1988

8. Castelnuovo P, Dallan I, Pistochini A, Battaglia P, Locatelli D, Bignami M: Endonasal endoscopic repair of Sternberg's canal cerebrospinal fluid leaks. Laryngoscope 117:345-349, 2007

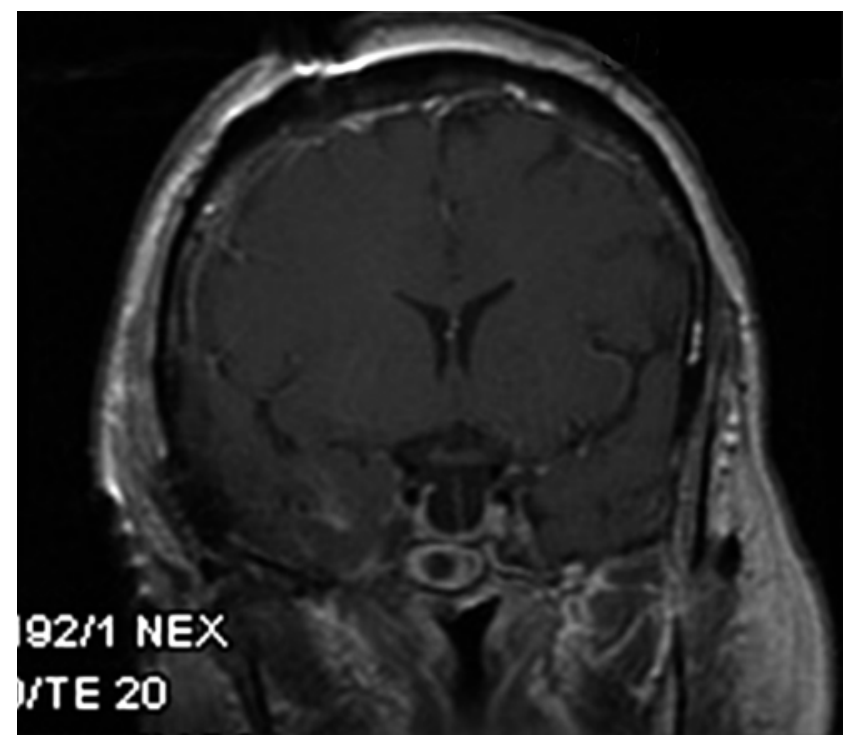

FIG. 3. Coronal T1-weighted MR image obtained after the encephalocele repair

9. Clyde BL, Stechison MT: Repair of temporosphenoidal encephalocele with a vascularized split calvarial cranioplasty: technical case report. Neurosurgery 36:202-206, 1995

10. D'Antonio M, Palacios E, Scheuemann C: CSF fistula secondary to sphenoid meningoencephalocele. Ear Nose Throat J 82:912-913, 2003

11. Elster AD, Branch CL Jr: Transalar sphenoidal encephaloceles: clinical and radiologic findings. Radiology 170:245-247, 1989

12. Firat AK, Firat Y: Spontaneous bilateral intrasphenoidal lateral encephaloceles: CT and MRI findings. Ear Nose Throat J 83:831-833, 2004

13. Gibson W Jr: Sphenoid sinus revisited. Laryngoscope 94: 185-191, 1984

14. Horky JK, Chaloupka JC, Putman CM, Roth TC: Occult spontaneous lateral temporal meningoencephalocele: MR findings of a rare developmental anomaly. AJNR Am J Neuroradiol 18:744-746, 1997

15. Hyson M, Andermann F, Olivier A, Melanson D: Occult encephaloceles and temporal lobe epilepsy: developmental and acquired lesions in the middle fossa. Neurology 34:363-366, 1984

16. Iurato S, Bux G, Colucci S, Dal Sasso A, Mevoli S, Onofri M, et al: Pathology of idiopathic encephaloceles into the middle ear. ORL J Otorhinolaryngol Relat Spec 64:73-79, 2002

17. Jackson CG, Pappas DG Jr, Manolidis S, Glasscock ME III, Von Doersten PG, Hampf CR, et al: Brain herniation into the middle ear and mastoid: concepts in diagnosis and surgical management. Am J Otol 18:198-206, 1997

18. Johnson DB, Brennan P, Toland J, O’Dwyer AJ: Magnetic resonance imaging in the evaluation of cerebrospinal fluid fistulae. Clin Radiol 51:837-841, 1996

19. Kamerer DB, Caparosa RJ: Temporal bone encephalocelediagnosis and treatment. Laryngoscope 92:878-882, 1982

20. Kantas I, Tzindros G, Papadopoulou A, Marangos N: Midfacial degloving: the best alternative for treatment of transsphenoidal meningocele of the pterygopalatine fossa. Skull Base 16:117-122, 2006

21. Kapadia SB, Janecka IP, Fernandes S, Curtin H, Pollack I: Lateral basal encephalocele of the infratemporal fossa. Otolaryngol Head Neck Surg 114:116-119, 1996

22. Kapur TR, Bangash W: Tegmental and petromastoid defects in the temporal bone. J Laryngol Otol 100:1129-1132, 1986 
23. Kaufman B, Nulsen FE, Weiss MH, Brodkey JS, White RJ, Sykora GF: Acquired spontaneous, nontraumatic normalpressure cerebrospinal fluid fistulas originating from the middle fossa. Radiology 122:379-387, 1977

24. Kaufman B, Yonas H, White RJ, Miller CF II: Acquired middle cranial fossa fistulas: normal pressure and nontraumatic in origin. Neurosurgery 5:466-472, 1979

25. Lai SY, Kennedy DW, Bolger WE: Sphenoid encephaloceles: disease management and identification of lesions within the lateral recess of the sphenoid sinus. Laryngoscope 112:1800 1805,2002

26. Landreneau FE, Mickey B, Coimbra C: Surgical treatment of cerebrospinal fluid fistulae involving lateral extension of the sphenoid sinus. Neurosurgery 42:1101-1105, 1998

27. Law AJ, Lee MA, Knuckey NW: Spontaneous CSF rhinorrhoea secondary to a middle cranial fossa defect. J Clin Neurosci 6:411-412, 1999

28. Leblanc R, Tampieri D, Robitaille Y, Olivier A, Andermann F, Sherwin A: Developmental anterobasal temporal encephalocele and temporal lobe epilepsy. J Neurosurg 74:933-939, 1991

29. Levy LM, Gulya AJ, Davis SW, LeBihan D, Rajan SS, Schellinger D: Flow-sensitive magnetic resonance imaging in the evaluation of cerebrospinal fluid leaks. Am J Otol 16:591596, 1995

30. Marchac D: Intracranial enlargement of the orbital cavity and palpebral remodeling for orbitopalpebral neurofibromatosis. Plast Reconstr Surg 73:534-543, 1984

31. Mayeno JK, Korol HW, Nutik SL: Spontaneous meningoencephalic herniation of the temporal bone: case series with recommended treatment. Otolaryngol Head Neck Surg 130:486-489, 2004

32. Moreano EH, Paparella MM, Zelterman D, Goycoolea MV: Prevalence of carotid canal dehiscence in the human middle ear: a report of 1000 temporal bones. Laryngoscope 104:612-618, 1994

33. Mortuaire G, Louis E, Pellerin P: Sphenoidal cerebrospinal fluid rhinorrhea: an original surgical approach. J Craniofac Surg 15:458-463, 2004

34. Motojima T, Fujii K, Ishiwada N, Takanashi J, Numata O, Uchino Y, et al: Recurrent meningitis associated with a petrous apex cephalocele. J Child Neurol 20:168-170, 2005

35. Mulcahy MM, McMenomey SO, Talbot JM, Delashaw JB Jr: Congenital encephalocele of the medial skull base. Laryngoscope 107:910-914, 1997

36. Mylanus EA, Marres HA, Vlietman J, Kollee LA, Freihofer HP, Thijssen HO, et al: Transalar sphenoidal encephalocele and respiratory distress in a neonate: a case report. Pediatrics 103:E12, 1999

37. Myssiorek D, Cohen NL: Intrasphenoidal meningoencephalocele: a case report. Am J Otolaryngol 8:391-394, 1987

38. Nager GT: Cephaloceles. Laryngoscope 97:77-84, 1987

39. Oberson R: Radioisotopic diagnosis of rhinorrhea. Radiol Clin Biol 41:28-35, 1972

40. Pasquini E, Sciarretta V, Farneti G, Mazzatenta D, Modugno GC, Frank G: Endoscopic treatment of encephaloceles of the lateral wall of the sphenoid sinus. Minim Invasive Neurosurg 47:209-213, 2004

41. Reynolds JM, Tomkinson A, Grigg RG, Perry CF: A Le Fort I osteotomy approach to lateral sphenoid sinus encephalocoeles. J Laryngol Otol 112:779-781, 1998

42. Rosenbaum TJ, Laxer KD, Rafal RD, Smith WB: Temporal lobe encephaloceles: etiology of partial complex seizures? Neurology 35:287-288, 1985
43. Roberti F, Potolicchio SJ, Caputy AJ: Tailored anteromedial lobectomy in the treatment of refractory epilepsy of the temporal lobe: long term surgical outcome and predictive factors. Clin Neurol Neurosurg 109:158-165, 2007

44. Ramones GH: Cunningham's textbook of anatomy. London: Oxford University Press, 1972, pp 130-131,139-140

45. Schick B, Draf W, Kahle G, Weber R, Wallenfang T: Occult malformations of the skull base. Arch Otolaryngol Head Neck Surg 123:77-80, 1997

46. Sdano MT, Pensak ML: Temporal bone encephaloceles. Curr Opin Otolaryngol Head Neck Surg 13:287-289, 2005

47. Short J, McKinney AM, Lucato LT, Teksam M, Truwit CL: Transalar encephalocele associated with Wegener granulomatosis and meningeal enhancement: case report. AJNR Am J Neuroradiol 26:1873-1875, 2005

48. Souliere CR Jr, Langman AW: Combined mastoid/middle cranial fossa repair of temporal bone encephalocele. Skull Base Surg 8:185-189, 1998

49. Soyer P, Dobbelaere P, Benoit S: Transalar sphenoidal encephalocele. Uncommon clinical and radiological findings. Clin Radiol 43:65-67, 1991

50. Soyer P, Dobbelaere P, Reizine D, Ferquel C: Transalar sphenoidal meningoencephalocele associated with buccal angiomatosis. One case. J Neuroradiol 17:222-226, 1990

51. Strandberg B: Cephalocele posterior orbitae; a general survey with report of a case. Acta Psychiatr Neurol 24:665-678, 1949

52. Tami TA: Surgical management of lesions of the sphenoid lateral recess. Am J Rhinol 20:412-416, 2006

53. Vallicioni JM, Girard N, Caces F, Braccini F, Magnan J, Chays A: Idiopathic temporal encephalocele: report of two cases. Am J Otol 20:390-393, 1999

54. Vergoni G, Antonelli V, Veronesi V, Servadei F: Spontaneous cerebrospinal fluid rhinorrhoea in anteromedial temporal occult encephalocele. Br J Neurosurg 15:156-158, 2001

55. Whiting DM, Awad IA, Miles J, Chou SS, Luders H: Intractable complex partial seizures associated with occult temporal lobe encephalocele and meningoangiomatosis: a case report. Surg Neurol 34:318-322, 1990

56. Wilkins RH, Radtke RA, Burger PC: Spontaneous temporal encephalocele. Case report. J Neurosurg 78:492-498, 1993

57. Yang E, Yeo SB, Tan TY: Temporal lobe encephalocoele presenting with seizures and hearing loss. Singapore Med J 45:40-42, 2004

58. Yeates AE, Blumenkopf B, Drayer BP, Wilkins RH, Osborne D, Heinz ER: Spontaneous CSF rhinorrhea arising from the middle cranial fossa: CT demonstration. AJNR Am J Neuroradiol 5:820-821, 1984

59. Zanetti D, Nassif N: Transmastoid repair of minor skull base defects with flexible hydroxyapatite sheets. Skull Base 13:111,2003

60. Zimmerman RA, Bilaniuk LT, Metzger RA, Grossman RI, Schut L, Bruce DA: Computed tomography of orbitalfacial neurofibromatosis. Radiology 146:113-116, 1983

Manuscript submitted August 12, 2008.

Accepted September 23, 2008.

Address correspondence to: Fabio Roberti, M.D., Department of Neurological Surgery, Suite 7-420, 2150 Pennsylvania Avenue NW, Washington, DC 20037. email: roberti.fabio@gmail.com. 